\title{
Resource Use Study In COPD (RUSIC): A prospective study to quantify the effects of COPD exacerbations on health care resource use among COPD patients
}

\author{
J Mark FitzGerald MB FRCPC ${ }^{1}$, Jennifer M Haddon MSc ${ }^{2}$, Carole Bradley-Kennedy MSc${ }^{2}$, \\ Lisa Kuramoto MSc ${ }^{1}$, Gordon T Ford MD FRCPC ${ }^{3}$, The RUSIC Study Group*
}

\begin{abstract}
JM FitzGerald, JM Haddon, C Bradley-Kennedy, L Kuramoto, GT Ford. Resource Use Study In COPD (RUSIC): A prospective study to quantify the effects of COPD exacerbations on health care resource use among COPD patients. Can Respir J 2007;14(3):145-152.
\end{abstract}

BACKGROUND: There is increasing interest in health care resource use (HRU) in Canada, particularly in resources associated with acute exacerbations of chronic obstructive pulmonary disease (COPD).

OBJECTIVE: To identify HRU due to exacerbations of COPD.

METHODS: A 52-week, multicentre, prospective, observational study of HRU due to exacerbations in patients with moderate to severe COPD was performed. Patients were recruited from primary care physicians and respirologists in urban and rural centres in Canada.

RESULTS: In total, 524 subjects (59\% men) completed the study. Their mean age was $68.2 \pm 9.4$ years, with a forced expiratory volume in $1 \mathrm{~s}$ of $1.01 \pm 0.4 \mathrm{~L}$. Patients had significant comorbidities. There were 691 acute exacerbations of COPD, which occurred in $53 \%$ of patients: 119 patients (23\%) experienced one acute exacerbation, 70 patients (13\%) had two acute exacerbations and 89 patients $(17 \%)$ had three or more acute exacerbations. Seventy-five patients were admitted to hospital, with an average length of stay of 13.2 days. Fourteen of the patients spent time in an intensive care unit (average length of stay 5.6 days). Factors associated with acute exacerbations of COPD included lower forced expiratory volume in $1 \mathrm{~s}(\mathrm{P}<0.001)$, high number of respiratory medications prescribed $(\mathrm{P}=0.037)$, regular use of oral corticosteroids (OCSs) $(\mathrm{P}=0.008)$ and presence of depression $(\mathrm{P}<0.001)$. Of the 75 patients hospitalized, only 53 received OCSs, four received referral for rehabilitation and 15 were referred for home care.

CONCLUSIONS: The present study showed a high prevalence of COPD exacerbations, which likely impacted on HRU. There was evidence of a lack of appropriate management of exacerbations, especially with respect to use of OCSs, and referral for pulmonary rehabilitation and home care.

Key Words: Chronic obstructive pulmonary disease; Exacerbations; Health care resource use
L'étude RUSIC sur l'utilisation des ressources en cas de MPOC : Une étude prospective pour quantifier les effets des exacerbations de MPOC sur l'utilisation des ressources de santé par les patients atteints d'une MPOC

HISTORIQUE : On s'intéresse de plus en plus à l'utilisation des ressources de santé (URS) au Canada, notamment aux ressources associées aux exacerbations aiguës de la maladie pulmonaire obstructive chronique (MPOC).

OBJECTIF : Repérer les URS imputables aux exacerbations d'une MPOC.

MÉTHODOLOGIE : On a mené une étude par observation prospective et multicentrique de 52 semaines sur l'URS causée par les exacerbations chez des patients atteints d'une MPOC modérée à grave. On a recruté les patients auprès de médecins de premier recours et de pneumologues de centres urbains et ruraux du Canada.

RÉSULTATS : Au total, 524 sujets (59\% d'hommes) ont terminé l'étude. Ils étaient d'un âge moyen de $68,2 \pm 9,4$ ans et avaient un volume

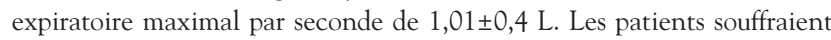
de comorbidités importantes. On a recensé 691 exacerbations aiguës de la MPOC, chez $53 \%$ des patients : 119 patients ( $23 \%$ ) ont subi une exacerbation aiguë, 70 (13\%) en ont subi deux et $89(17 \%)$, trois ou quatre. Soixante-quinze patients ont été hospitalisés, pendant une moyenne de 13,2 jours. Quatorze des patients ont passé du temps à l'unité de soins intensifs (séjour moyen de 5,6 jours). Les facteurs associés aux exacerbations aiguës de la MPOC sont un volume expiratoire maximal par seconde plus faible $(\mathrm{P}<0,001)$, un grand nombre de médicaments respiratoires prescrits $(\mathrm{P}=0,037)$, l'utilisation régulière de corticoïdes oraux $(\mathrm{CO})(\mathrm{P}=0,008)$ et la présence de dépression $(\mathrm{P}<0,001)$. Sur les 75 patients hospitalisés, seulement 53 ont reçu des $\mathrm{CO}$, quatre ont été orientés vers une réadaptation pulmonaire et 15 , vers des soins à domicile. CONCLUSIONS : La présente étude démontre une forte prévalence d'exacerbations de MPOC, qui ont probablement des répercussions sur l'URS. On a constaté des éléments probants d'absence de prise en charge pertinente des exacerbations, notamment pour ce qui est du recours aux $\mathrm{CO}$ et aux orientations vers une réadaptation pulmonaire et des soins à domicile.

throughout the world. On the worldwide ranking list of disabilityadjusted life years, COPD is predicted to rise from 12th place in 1990 to fifth place in 2020 (2). COPD has received much less attention than asthma, yet the former is a major cause of morbidity and mortality throughout the world and in Canada (1,3-5). The cost per patient has been shown to be three times higher with COPD than with asthma.

* See Appendix for the full list of investigators

${ }^{1}$ Centre for Clinical Epidemiology and Evaluation, Vancouver Coastal Health Research Institute, University of British Columbia, Vancouver,

British Columbia; ${ }^{2}$ Boehringer Ingelheim (Canada) Limited, Burlington, Ontario; ${ }^{3}$ Respiratory Division, University of Calgary, Calgary, Alberta

Correspondence and reprints: Dr J Mark FitzGerald, Respiratory Division, Vancouver General Hospital, Centre for Clinical Epidemiology and Evaluation, Research Pavilion, 828 - West 10th Avenue, Vancouver, British Columbia V5Z 1L8. Telephone 604-875-4565,

fax 604-875-5179, e-mail markf@interchange.ubc.ca 


\section{TABLE 1}

\section{Inclusion and exclusion criteria}

Inclusion criteria

- All patients were required to give written informed consent before participation in the study

- All patients had a diagnosis of stable chronic obstructive pulmonary disease in their charts and had met the following spirometric criteria: airway obstruction with an $\mathrm{FEV}_{1}$ of $49 \%$ or less and an $\mathrm{FEV}_{1} / \mathrm{FVC}$ of $70 \%$ or less (amendment \#1 at study initiation changed the required $\mathrm{FEV}$ to $65 \%$ or less to increase recruitment and to obtain a less severe population). A pulmonary function test performed within six months before or 10 days after visit 1 was deemed acceptable

- Male or female patients aged 40 years or older

- Patients were current or ex-smokers with a smoking history of more than 10 pack-years

Exclusion criteria

- Patients with a history of asthma, cystic fibrosis, bronchiectasis, interstitial lung disease or pulmonary thromboembolic disease

- Patients with any other known condition or circumstance that would, in the investigator's opinion, prevent compliance or completion of the study

- Patients who had taken an investigational drug within 30 days of the screening visit

- Patients who were participating in another study

- Patients who wished to take part in another clinical trial

- Patients who were expected to stay outside of Canada for eight consecutive weeks or longer (because only Canadian health care resource use data was collected)

FEV 1 Forced expiratory volume in 1 s; FVC Forced vital capacity

Exacerbations are common in patients with COPD. An exacerbation is associated with symptoms, such as increased dyspnea, cough and sputum, as well as changes in sputum colour. The frequency of COPD exacerbations has also been associated with worsening of pulmonary function (6). Consequently, COPD has a major impact on health care use. Exacerbations of COPD due to therapeutic failures, particularly those that result in hospitalization, are the primary cost drivers in this disease (7). In Canada, COPD is the third and fifth leading cause of hospitalizations for men and women, respectively. It accounts for $12.5 \%$ of male and $7.7 \%$ of female hospitalizations, as well as $5 \%$ of physician visits. A recent study (8) has shown that $59 \%$ of COPD patients discharged from hospital after an exacerbation were readmitted at least once during the following year. Furthermore, the trend is increasing; there were 55,785 separate hospitalizations in 1993 to 1994 with COPD as the primary discharge diagnosis, compared with 42,102 in 1981 to 1982 (an increase of 32\%) (4). Again, this is noteworthy among women (the increase was $67 \%$, which was $25 \%$ when standardized by age) and among those older than 75 years in both sexes.

Currently, there is no pharmacological therapy that completely prevents the occurrence of exacerbations of COPD, although some treatments have been shown to reduce their frequency $(9,10)$.

The objective of the present study was to identify and quantify the health care resource use (HRU) due to moderate to severe exacerbations of COPD. These included clinical, emergency department (ED) and hospital visits due to moderate to severe exacerbations.

\section{Study design and plan}

\section{METHODS}

This was a 52-week, multicentre, prospective, observational study of HRU due to exacerbations in patients with COPD. To get a varied sample of cases, patients were prospectively recruited from four major sources: urban primary care settings, rural primary care settings, community- and academically based respirologists. There were 50 sites in 10 provinces that recruited patients from June 2001 to September 2002. The physicians were instructed to "enter the next successive eight to 10 eligible patients meeting all inclusion criteria and none of the exclusion criteria" (Table 1) during regular clinical visits. This first visit was called the screening visit (visit 1), when eligible and consenting patients were enrolled into the 52-week observational study.

Subsequent clinical visits were scheduled approximately 17 weeks apart. To ensure optimal capturing of exacerbation data between clinical visits, patients were contacted by telephone to obtain information at five- to six-week intervals regarding exacerbations, health facility use and days away from activities due to exacerbations of COPD. The patients were given a diary to record the details of their HRU to improve the accuracy of their recall during telephone contact. Forced expiratory volume in $1 \mathrm{~s}\left(\mathrm{FEV}_{1}\right)$ and forced vital capacity (FVC) measurements were obtained through pulmonary function testing (PFT) at visit 1 . The sites were permitted to use historical spirometry results from the patient's chart if the spirometry test had been completed within the previous six months. If the site did not have a historical spirometry assessment for a patient, they were permitted to refer the patient to an external PFT laboratory within 10 days after visit 1 to have the lung function assessment completed. PFT was performed using calibrated electronic spirometers with the patient in a seated position, but the spirometers were not required to be a specific model. The lung function tests were done in triplicate, and the largest $\mathrm{FEV}_{1}$ and $\mathrm{FVC}$ values were recorded after examining all the acceptable curves using the American Thoracic Society criteria (11), even if not from the same curve (with a maximum of five attempts).

\section{Definition of an exacerbation}

An exacerbation was defined as a complex of COPD-related symptoms, including one or more of the following: cough, wheeze, dyspnea (chest congestion, shortness of breath or chest tightness) or sputum production lasting three days or longer. Exacerbations were categorized as mild, moderate or severe according to the following definitions commonly used by the Boehringer Ingelheim in their clinical trial programs:

- Moderate - visit to an outpatient facility, including an ED (but not requiring admission to hospital), and an alteration in medication (eg, addition of antibiotics or oral corticosteroids [OCSs]); and

- Severe - hospitalization. 
Only data for HRU as a result of moderate to severe exacerbations were collected. Data regarding HRU were collected prospectively in a standardized fashion. Records of patients who experienced an exacerbation were reviewed, and the medications prescribed and outcomes were documented. All concomitant medications taken were recorded in the concomitant therapy case report form, including rescue use of short-acting, inhaled beta-agonists. Patients with at least one exacerbation were described as exacerbators, and those without any exacerbations were classified as nonexacerbators.

\section{HRU questionnaire}

Information on nonscheduled contacts with physicians and other health care providers that were due to an exacerbation of COPD, including date, reason for contact, medications prescribed, outcome (eg, discharge, admission to hospital, follow-up visit), disability days and employment status was collected prospectively using a standardized questionnaire.

\section{Health care facility definition}

The health care facility definition was determined by any of the three following conditions:

- Inpatient hospitalization - for each inpatient admission, the primary and associated diagnoses were abstracted (from the discharge summary), and the length of stay and COPD-related complications were documented. Intensive care unit admission and mechanical ventilator support (invasive and noninvasive), and their durations of use were also collected;

- ED visits - each ED visit was recorded. Based on the medical notes, the reason for consultation was documented and the duration of ED attendance was noted; and

- Day treatment - use of day treatment facilities (ie, day hospital, ambulatory treatment centre and physiotherapy) was recorded as for ED visits, and each unscheduled walk-in clinical visit for COPD was noted.

\section{Statistical analyses}

Data were analyzed using SAS version 8.02 (SAS Institute Inc, North Carolina, USA).

\section{Primary analyses}

The proportion of patients experiencing a COPD exacerbation and the proportion with at least one hospitalization resulting from a COPD exacerbation were estimated. Ninety-five per cent CIs were calculated for these quantities. Histograms showing the distributions of the number of COPD exacerbations and frequencies showing the number of hospitalizations were calculated.

\section{Secondary analyses}

A number of secondary analyses were also performed, including:

- The proportion of patients requiring exacerbationattributable, outpatient concomitant respiratory medications (including antibiotics, OCSs or supplemental oxygen), by type of medication;

- The proportion of patients requiring exacerbationattributable (referral was triggered by an exacerbation), home care and/or inpatient and/or outpatient hospital rehabilitation, including physiotherapy visits related to an

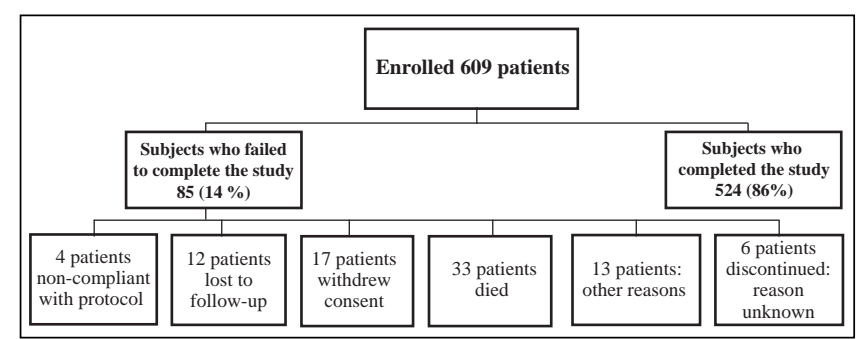

Figure 1) Study population: Details of exclusion of subjects

exacerbation of COPD and the mean number of days required;

- The mean number of lost usual activity days and productivity days due to COPD exacerbations;

- The comparison of baseline characteristics between exacerbators and nonexacerbators. A two-sample $t$ test was used to compare means of continuous variables, such as $\mathrm{FEV}_{1}$. A $\chi^{2}$ test was used to assess the association with categorical variables, such as regular use of OCSs;

- The association between COPD exacerbations and respiratory medications, adjusted for confounding variables. Logistic regression was used to adjust for age, sex, body mass index (BMI) and $\mathrm{FEV}_{1}$; and

- The association between number of exacerbations and concomitant respiratory medications. Poisson regression with overdispersion was used to model the number of exacerbations.

\section{Sample size estimates}

The determinant for the sample size calculation was the need to estimate the proportion of patients in the sample with COPD exacerbations - because this is the driver for the resource use - with a level of accuracy acceptable for pharmacoeconomic modelling.

The primary result of interest was the first occurrence of a COPD exacerbation. Using the usual normal approximation to the binomial distribution (valid for large samples), the $95 \% \mathrm{CI}$ for a proportion $(\mathrm{P})$ is given by $\mathrm{P} \pm 1.96 \sqrt{ }(\mathrm{P}[1-\mathrm{P}] / \mathrm{n})$, in which $\mathrm{n}$ is the sample size, $\mathrm{P}$ is expected to be approximately $40 \%$ and an acceptable $95 \%$ CI width for $\mathrm{P}$ is $8 \%$. This led to a required sample size of 594 patients.

\section{Informed consent}

Approval for the study was obtained either from the institutional ethics board for investigators affiliated with an academic centre or from a central ethics board for community-based investigators. Before subject participation in the trial, written informed consent was obtained from each subject (or the subject's legally accepted representative). A signed copy of the informed consent and any additional subject information was given to each subject or the subject's legally authorized representative.

\section{Study subjects}

\section{RESULTS}

A total of 609 patients were enrolled in the study. Eighty-five patients (14.0\%) did not complete the study for various reasons (Figure 1). Baseline characteristics are shown in Table 2, patients' comorbidities are shown in Table 3 and medications taken at baseline are shown in Table 4 . 


\section{TABLE 2}

Demographics (all patients who completed the study)*

\begin{tabular}{lc}
\hline Characteristic & Mean \pm SD \\
\hline Age (years) & $68.2 \pm 9.4$ \\
Smoking history (pack-years) & $47.1 \pm 22.8$ \\
Body mass index $\left(\mathrm{kg} / \mathrm{m}^{2}\right)$ & $26.6 \pm 6.3$ \\
FEV $_{1}(\%$ predicted) & $43.9 \pm 14.3$ \\
FVC $(\%$ predicted) & $64.6 \pm 16.9$ \\
FEV & $(\mathrm{L})$ \\
FVC $(L)$ & $1.044 \pm 0.413$ \\
FEV $/$ FVC $(\%)$ & $2.239 \pm 0.772$ \\
Sex & $47.4 \pm 11.2$ \\
\hline Male & $\mathbf{n}(\%)$ \\
Female & $309(59)$ \\
\hline
\end{tabular}

*Eighty-five patients failed to complete the study, with a mean $\pm S D$ forced expiratory volume in $1 \mathrm{~s}\left(F E V_{1}\right)$ of $0.92 \pm 0.44 L$ and a mean age of 71 years. Of these noncompleted, 33 patients died and their FEV 1 was 0.81 L. FVC Forced vital capacity

TABLE 3

Concomitant diagnoses (all patients who completed the study)

\begin{tabular}{lc}
\hline Medical Directory of Regulary Activities body system & $\mathbf{n ~ ( \% )}$ \\
\hline Musculoskeletal and connective tissue disorders & $257(49.0)$ \\
Vascular disorders & $234(44.7)$ \\
Metabolism and nutrition disorders & $165(31.5)$ \\
Gastrointestinal disorders & $162(30.9)$ \\
Cardiac disorders & $148(28.2)$ \\
Psychiatric disorders & $114(21.8)$ \\
Nervous system disorders & $86(16.4)$ \\
Neoplasms benign, malignant and unspecified & $54(10.3)$ \\
$\quad$ (including cysts and polyps) & \\
Other & $346(66.0)$ \\
\hline
\end{tabular}

Of the 524 patients who completed the study, 366 $(69.8 \%)$ saw a family physician and $158(30.2 \%)$ saw a specialist. The average $( \pm \mathrm{SD}) \mathrm{FEV}_{1}$ among patients who saw a family physician was $1.07 \pm 0.43 \mathrm{~L}$ and the average $\mathrm{FEV}_{1}$ among patients who saw a specialist was $0.98 \pm 0.36 \mathrm{~L}$, which was significantly different between the groups $(\mathrm{P}=0.0064)$. Based on the Canadian Thoracic Society criteria (1) for COPD severity there were 70 'mild patients', 218 'moderate patients' and 227 'severe patients'. The average number of exacerbations increased with COPD severity; mild patients had $1.0 \pm 1.9$ exacerbations, moderate patients had $1.2 \pm 1.9$ exacerbations and severe patients had $1.5 \pm 2.4$ exacerbations, and the association between COPD severity and the number of exacerbations was significant $(\mathrm{P}=0.0125)$. In keeping with this, $15.6 \%$ and $30 \%$ of moderate and severe patients, respectively, visited the ED. Similarly, $10.1 \%$ and $21.2 \%$ of moderate and severe patients, respectively, were admitted to hospital.

In terms of activity, $64.2 \%$ of patients were retired but not due to COPD, $14.7 \%$ were still employed, $9.8 \%$ were retired due to COPD and 3.6\% were disabled due to COPD.
TABLE 4

Previous and concomitant therapy (all patients who completed the study)

\begin{tabular}{lc}
\hline Concomitant therapy category & $\mathbf{n}^{*}(\%)$ \\
\hline Respiratory therapy & $285(54.4)$ \\
ICSs & $246(46.9)$ \\
Salbutamol & $222(42.4)$ \\
Ipratropium bromide & $198(37.8)$ \\
Combined salbutamol and ipratropium bromide & $152(29.0)$ \\
LABA & $79(15.1)$ \\
Combination of ICSs and LABA & $66(12.6)$ \\
Theophylline & $45(8.6)$ \\
Prednisone & $45(8.6)$ \\
Oxygen & \\
Nonrespiratory therapy & $137(26.1)$ \\
ACE inhibitor (antihypertensive agent) & $125(23.9)$ \\
Acetylsalicylic acid & $93(17.7)$ \\
Statin (lipid-lowering agent) & $80(15.3)$ \\
Calcium channel blocker (antihypertensive agent) & $63(12.0)$ \\
Treatment for osteoporosis ${ }^{\dagger}$ & $61(11.6)$ \\
Sedative & $60(11.5)$ \\
Nonsteroidal anti-inflammatory drug & $56(10.7)$ \\
Proton pump inhibitor & $49(9.4)$ \\
Furosemide & $48(9.2)$ \\
Hydrogen & -receptor antagonist \\
Other & $420(80.2)$ \\
\hline
\end{tabular}

${ }^{*}$ Number of patients with at least one therapy; ${ }^{\dagger}$ All treated with bisphosphate agents. ACE Angiotensin-converting enzyme; ICSs Inhaled corticosteroids; LABA Long-acting beta -agonist

Exacerbations and HRU

During the year-long study, 691 moderate to severe acute exacerbations of COPD were reported, which occurred in 278 patients $(53.1 \%) ; 246$ patients $(46.9 \%)$ experienced no exacerbations. There were 1.3 moderate to severe exacerbations and 0.2 hospitalizations per patient; however, when the exacerbator group was examined alone, the numbers increased substantially (2.5 exacerbations and 1.5 hospitalizations). Figure 2 shows the number of exacerbations among the exacerbators, with $18.4 \%$ of the patients having four or more exacerbations per year. Figure 3 shows exacerbators' use of at least one type of health care resource at the time of the exacerbation.

There were 75 hospitalizations, and six patients had three or more hospitalizations (Table 5).

Overall, there were a total of 193 visits to the ED and 112 hospitalizations. The mean length of stay was $13.2 \pm 19.2$ days, and the median length of stay was eight days, with a range of two to 130 days. Among patients hospitalized, $14(18.7 \%)$ required admission to the intensive care unit, and seven of these patients required intubation.

Exacerbators and nonexacerbators

Differences in baseline characteristics between exacerbators and nonexacerbators are shown in Table 6. Exacerbators were no different from nonexacerbators in terms of smoking history and age. Patients with a lower BMI $\left(26.0 \pm 6.1 \mathrm{~kg} / \mathrm{m}^{2}\right.$ versus $\left.27.2 \pm 6.5 \mathrm{~kg} / \mathrm{m}^{2}, \mathrm{P}=0.023\right)$, lower $\mathrm{FEV}_{1}(1.0 \pm 0.3 \mathrm{~L}$ versus $1.1 \pm 0.5 \mathrm{~L}, \mathrm{P}<0.001)$ and a lower $\mathrm{FEV}_{1} / \mathrm{FVC}$ ratio $(45.1 \pm 10.5$ 


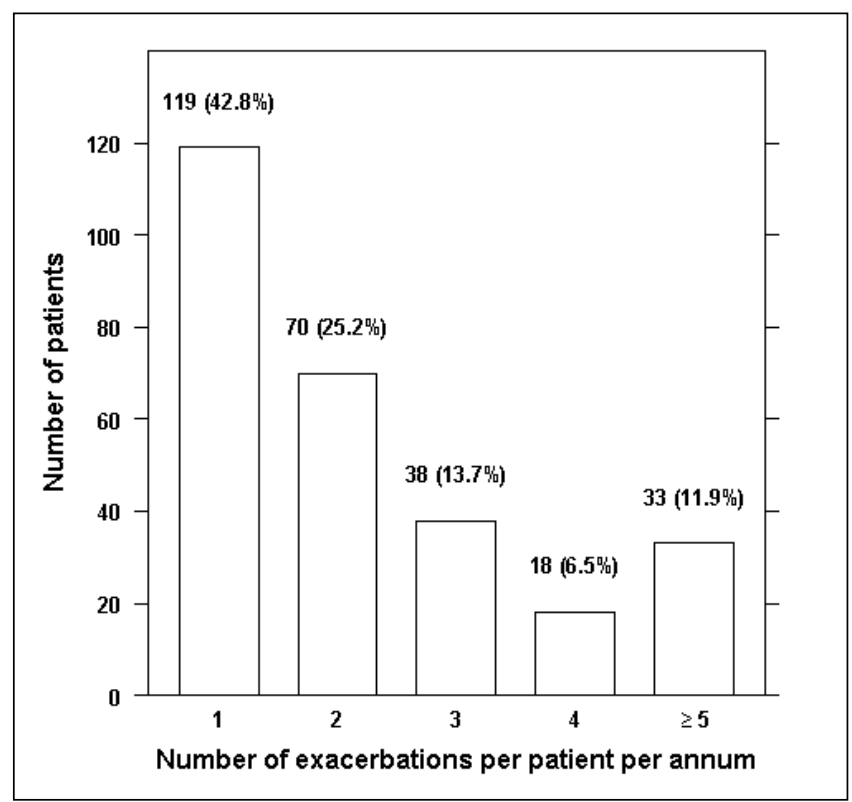

Figure 2) Distribution of the number of chronic obstructive pulmonary disease exacerbations per patient per annum among exacerbators

versus $50.0 \pm 11.3, \mathrm{P}<0.001)$ were more likely to exacerbate. In addition, patients on OCSs (versus no OCSs) were more likely to exacerbate $(\mathrm{n}=35[12.6 \%]$ versus $\mathrm{n}=10[4.1 \%]$, respectively, $\mathrm{P}=0.001)$, even after adjustment for $\mathrm{FEV}_{1}(\mathrm{P}=0.008)$. When the number of exacerbations was modelled using Poisson regression (with over-dispersion) and adjusted for $\mathrm{FEV}_{1}$, use of ICSs, long-acting beta 2 -agonists (LABAs), a combination of ICSs and LABAs, and the presence of a comorbidity were not significantly associated with the absolute number of exacerbations.

The type of treatment prescribed in the three different care settings (clinical, ED and hospital) is shown in Table 7.

Only 17 patients (3.2\%) were prescribed professional home care, and four (5.3\%) received rehabilitation. Seven of 77 patients $(9.0 \%)$ who were working had to stop because of their COPD.

\section{DISCUSSION}

In the present year-long prospective study, we have documented the baseline characteristics and health outcomes for a large cohort of Canadian COPD patients. The results of the present study confirm previous reports of significant morbidity in this patient population (12). In part, this likely reflects the age of the cohort, but it also highlights the need to consider COPD management not only in the context of COPD but also the impact of other chronic conditions.

In addition, the challenge of managing these patients was highlighted by the significant number of comorbidities in this patient population. The presence of comorbidities was associated with increased risks of exacerbation and hospitalization, and highlights the challenge of managing these patients, especially with the coexistence of congestive heart failure, in which symptoms and signs may overlap with those of a COPD exacerbation. Greater than $20 \%$ of patients had psychiatric illness recorded as a comorbidity. This increased risk of depression in COPD patients has previously been reported (13). The link between exacerbations and depression has not been

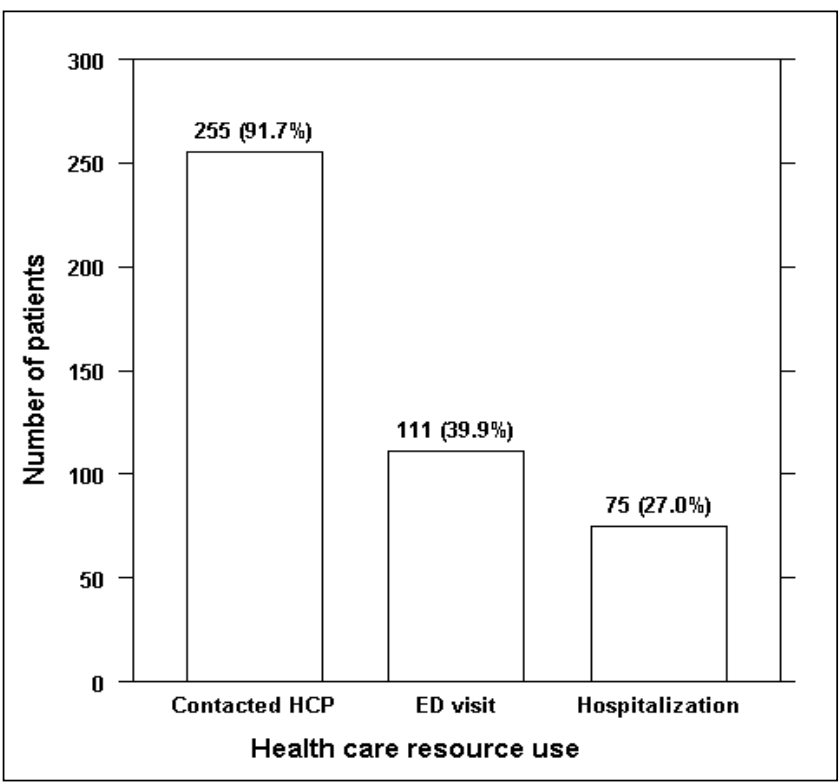

Figure 3) Exacerbators' use of at least one type of health care resource at the time of the exacerbation. ED Emergency department; HCP Health care practitioner

TABLE 5

Proportion of hospitalizations by 'exacerbators'

\begin{tabular}{lccc}
\hline Hospitalization & $\mathbf{n}$ & $\%^{*}$ & $\mathbf{9 5 \%} \mathbf{C l}$ \\
\hline Number of hospitalizations & 75 & 27.0 & 24.3 to 29.6 \\
1 & 50 & 18.0 & 15.7 to 20.3 \\
2 & 19 & 6.8 & 5.3 to 8.3 \\
$\geq 3$ & 6 & 2.2 & 1.3 to 3.0 \\
Rehabilitation & 4 & 1.4 & 0.7 to 2.2 \\
No oral corticosteroids & 22 & 7.9 & 6.3 to 9.5 \\
\hline
\end{tabular}

*Percentages are based on total number of patients who exacerbated ( $n=278)$

reported previously, and it is unclear whether this is a consequence of COPD. Further study of this relationship is required to assess this issue. Similarly, the increased proportion of patients with COPD exacerbations who had a history of gastrointestinal complaints may be of importance. The need for further research in this area has been identified (14).

Most patients $(99.6 \%)$ were taking a bronchodilator (including theophylline, LABAs, salbutamol, ipratropium bromide, or combined salbutamol and ipratropium bromide) and a significant proportion were on ICSs, even though these are not recommended by current treatment guidelines as first-line treatment for COPD, except in patients with severe disease who suffer repeated exacerbations (15). Increased prescription of respiratory therapies is usually an indication of more severe disease.

The lack of a standard definition for acute exacerbations of COPD and of a severity grading system contribute to the difficulty in assessing the real impact of these episodes, both on patients with COPD and on the health care system, as noted by de Melo et al (16). They retrospectively assessed 5645 patients for 3.7 years using the databases of Saskatchewan Health. Using a similar definition for moderate to severe COPD exacerbations, they reported an average of 1.12 moderate to severe exacerbations per person-year, which was comparable with our 


\section{TABLE 6}

Characteristics of nonexacerbators versus exacerbators (all patients who completed the study)

\begin{tabular}{|c|c|c|c|}
\hline Characteristics & Ionexacerbators & Exacerbators & $\mathbf{P}$ \\
\hline Age, years $($ mean $\pm S D)$ & $68.1 \pm 9.4$ & $68.3 \pm 9.4$ & $0.802^{*}$ \\
\hline $\begin{array}{l}\text { Smoking history, pack-years } \\
\text { (mean } \pm \mathrm{SD})\end{array}$ & $46.3 \pm 23.3$ & $47.8 \pm 22.4$ & $0.340^{*}$ \\
\hline Body mass index, $\mathrm{kg} / \mathrm{m}^{2}$ (mean $\left.\pm \mathrm{SD}\right)$ & D) $27.2 \pm 6.5$ & $26.0 \pm 6.1$ & $0.023^{*}$ \\
\hline $\mathrm{FEV}_{1}, \%$ predicted (mean $\pm \mathrm{SD}$ ) & $46.8 \pm 15.2$ & $41.4 \pm 13.1$ & $<0.001^{*}$ \\
\hline FVC, $\%$ predicted $($ mean \pm SD) & $65.1 \pm 16.4$ & $64.2 \pm 17.3$ & $0.55^{\star}$ \\
\hline $\mathrm{FEV}_{1}, \mathrm{~L}($ mean $\pm \mathrm{SD})$ & $1.1 \pm 0.5$ & $1.0 \pm 0.3$ & $<0.001^{*}$ \\
\hline FVC, L (mean $\pm \mathrm{SD})$ & $2.3 \pm 0.8$ & $2.2 \pm 0.7$ & $0.050^{*}$ \\
\hline $\mathrm{FEV}_{1} / \mathrm{FVC}, \%($ mean $\pm \mathrm{SD})$ & $50.0 \pm 11.3$ & $45.1 \pm 10.5$ & $<0.001^{*}$ \\
\hline \multicolumn{4}{|l|}{ Sex, n (\%) } \\
\hline Male & $154(62.6)$ & $155(55.8)$ & $0.112^{\dagger}$ \\
\hline Female & $92(37.4)$ & $123(44.2)$ & \\
\hline \multicolumn{4}{|l|}{ Inhaled corticosteroids, n (\%) } \\
\hline Absence & $123(50.0)$ & $116(41.7)$ & $0.058^{\dagger}$ \\
\hline Presence & $123(50.0)$ & $162(58.3)$ & \\
\hline \multicolumn{4}{|l|}{ Oral corticosteroids, n (\%) } \\
\hline Absence & $236(95.9)$ & $243(87.4)$ & $0.001^{\dagger}$ \\
\hline Presence & $10(4.1)$ & $35(12.6)$ & \\
\hline \multicolumn{4}{|l|}{ Number of morbidities, $\mathrm{n}(\%)$} \\
\hline 0 & $28(11.4)$ & $37(13.3)$ & $0.024^{t}$ \\
\hline 1 & $69(28.0)$ & $49(17.6)$ & \\
\hline 2 & $65(26.4)$ & $72(25.9)$ & \\
\hline$\geq 3$ & $84(34.1)$ & $120(43.2)$ & \\
\hline
\end{tabular}

${ }^{*}$ Two-sample $\mathrm{t}$ test; ${ }^{\dagger} \chi^{2}$ test. FEV ${ }_{1}$ Forced expiratory volume in $1 \mathrm{~s}$; FVC Forced vital capacity

average finding of 1.3 exacerbations per person-year among all subjects $(0.102$ exacerbations per person-year for hospitalizations compared with our study of 0.2 exacerbations per personyear). However, there appear to be two distinct groups of patients, exacerbators and nonexacerbators. When the rate of exacerbations was quantified solely in the exacerbators, the frequency increased dramatically from 1.3 to 2.5 exacerbations per person-year (and hospitalizations jumped from 0.2 to 1.5 exacerbations per person-year) in our study.

The identification of this increased risk with frequent exacerbators is important because increased frequency of COPD exacerbations has been associated with a faster rate of decline in lung function (6). Predictors of exacerbation in the present study included having a lower $\mathrm{FEV}_{1}$, a lower BMI and chronic treatment with OCSs. The presence of OCSs does appear to be a good predictor of future exacerbations, but this only accounts for $12.6 \%$ of the group and likely reflects the more severe patients and confounding by indication. However, the statistical differences between the groups for most of the predictors may not be considered clinically meaningful (ie, $100 \mathrm{~mL}$ difference in $\mathrm{FEV}_{1}, 1.2 \mathrm{~kg} / \mathrm{m}^{2}$ difference in $\mathrm{BMI}$ ). Therefore, the clinician may not be able to predict which patient will be the 'exacerbator' with subsequent high resource use.

Many of the sites did not complete the subject enrolment $\log$ in which they were to record the reasons for not entering a screened patient into the study. Therefore, it is not possible to determine the ratio of patients screened to patients enrolled or approached and refused.
TABLE 7

Type of treatment received by subjects, related to place of treatment, at the time of exacerbation

\begin{tabular}{|c|c|c|c|}
\hline & $\begin{array}{c}\text { Health } \\
\text { professional } \\
(n=255)\end{array}$ & $\begin{array}{c}\text { Emergency } \\
\text { department } \\
(n=111)\end{array}$ & $\begin{array}{c}\text { Hospital } \\
(n=75)\end{array}$ \\
\hline Type of respiratory treatment & $n^{*}(\%)^{\dagger}$ & $\mathrm{n}^{*}(\%)^{\dagger}$ & $\mathrm{n}^{*}(\%)^{\dagger}$ \\
\hline Any respiratory treatment & 235 (92.2) & $89(80.2)$ & $68(90.7)$ \\
\hline Beta $_{2}$-agonist (SABA and LABA) & $44(17.3)$ & $62(55.9)$ & $51(68.0)$ \\
\hline Anticholinergic (SAAC only) & $16(6.3)$ & $52(46.8)$ & $50(66.7)$ \\
\hline Theophylline & $8(3.1)$ & $3(2.7)$ & $6(8.0)$ \\
\hline Corticosteroids & $110(43.1)$ & $51(45.9)$ & $53(70.7)$ \\
\hline Leukotriene-receptor antagonist & $5(2.0)$ & $1(0.9)$ & $1(1.3)$ \\
\hline Antibiotics & $204(80.0)$ & $53(47.7)$ & $60(80.0)$ \\
\hline Oxygen & $12(4.7)$ & $64(57.7)$ & $57(76.0)$ \\
\hline Other & 43 (16.9) & $28(25.2)$ & $22(29.3)$ \\
\hline
\end{tabular}

*Number of patients with at least one treatment; ${ }^{+}$Percentages based on total number of patients with at least one exacerbation of the same type. LABA Long-acting beta ${ }_{2}$-agonist; SAAC Short-acting anticholinergic; SABA Shortacting beta ${ }_{2}$-agonist

The results clearly demonstrate that in all treatment settings (physicians' offices, ED and hospital), patients were significantly undertreated for exacerbations. Despite the proven benefit of OCSs at the time of an exacerbation (17-19), only 53 patients $(71 \%)$ received such treatment when they were hospitalized. This proportion was even lower if treatment occurred in a physician's office or in an ED $(43 \%$ and $46 \%$, respectively). The comparatively high use of antibiotics was interesting because although the majority of exacerbations in COPD patients are associated with bacterial infection, a significant minority are caused by viruses (20). Despite the fact that the etiology of the exacerbation was not assessed for all patients, antibiotics were still used in $80 \%$ of the patients who were hospitalized, $80 \%$ of the patients who visited a physician's office and $48 \%$ of the patients who visited an ED. In a classic study, Anthonisen et al (21) clearly showed that antibiotics were effective in patients with increased sputum, dyspnea and sputum purulence.

These data suggest that there is a significant opportunity to improve both the inpatient and the outpatient management of COPD exacerbations. These results are validated by a recent retrospective study (22) of a group of Canadian patients admitted to hospital with a COPD exacerbation; in this study, a significant care gap was identified. Greater rates of use of OCSs, such as prednisone, to treat exacerbations in COPD would likely lead to reduced number of ED visits and hospital admissions, and more comprehensive use of systemic corticosteroids may be associated with a reduced length of hospital stay.

There may have been some recall bias regarding the details of health care practioner contacts because there would not necessarily be a written medical report. However, the patients were contacted by telephone every five to six weeks to obtain details of their exacerbations and their health facility use to optimize data collection. It is assumed that major events, such as an admission to the hospital, would not be omitted, but the moderate exacerbations could be under-reported.

In addition to pharmacotherapy for COPD patients, there is increasing interest in the development of chronic disease management models for different conditions. Whereas a systematic review of self-management education programs in COPD by 
Monninkhof et al (23) produced inconclusive results, a study from Quebec (24) demonstrated significant benefits associated with a COPD-specific educational intervention. In their study, the use of a disease-specific self-management intervention was associated with a $39.8 \%$ reduction in hospitalizations in the intervention group compared with the usual care group, as well as a $57.1 \%$ reduction in admissions for other health-related problems, a $41.0 \%$ reduction in ED visits and a $58.9 \%$ reduction in unscheduled physician visits. The role of pulmonary rehabilitation in improving health-related quality of life and overall outcome in COPD patients has been well documented $(25,26)$. It is, therefore, disappointing in the present study to see the very low use of any community service, such as home care or pulmonary rehabilitation. Although pulmonary rehabilitation has not been shown to reduce hospitalizations in COPD patients, it has been shown to provide clinically meaningful and statistically significant improvements in healthrelated quality of life, functional exercise capacity and maximum exercise capacity $(25,26)$.

The present study identifies a significant burden of illness among a large cohort of COPD patients. It identifies significant care gaps between what are known to be effective treatments for COPD patients at the time of exacerbations and current treatment, which likely impacted on HRU. With a rising proportion of patients, especially women, developing COPD, it is clear that a more evidence-based strategy for the management of COPD is required. Recent publication of such guidelines is a positive sign in terms of outlining the optimal strategy for patient care $(1,15)$. The significant impact that COPD exacerbations have on the decline in lung function and patients' quality of life has been documented (6,27). More recently, Spanish investigators (28) have confirmed for the first time that the risk of death is significantly associated with COPD exacerbations, reinforcing the need to identify strategies to better characterize these events, and to develop and implement strategies to reduce their frequency. As the current study shows, the challenge to implement evidence-based medicine still remains. The implementation of effective educational programs for this complex group of patients with multiple comorbidities is urgent. Physicians need to be better educated regarding the initial management of exacerbations and, especially, the earlier use of OCSs. In addition, the development of a network of pulmonary rehabilitation centres $(1,26)$ for these patients to access is required if we are to improve these patients' quality of life.

\section{CONCLUSIONS}

The present study showed a high prevalence of COPD exacerbations, which likely impacted on HRU. There was evidence of a lack of appropriate management of exacerbations, especially with regard to the use of OCSs and referrals for pulmonary rehabilitation and home care. As the prevalence of COPD increases in the population and available resources become more limited, we urgently need new models of chronic care management of COPD to reduce the frequency of COPD exacerbations and, when they occur, to treat them earlier and more effectively.

ACKNOWLEDGEMENTS: This study was funded by Boehringer Ingelheim Canada Limited and Pfizer Canada. The data were analyzed independently at the Centre for Clinical Epidemiology and Evaluation, University of British Columbia, Vancouver, British Columbia. Professor FitzGerald holds a British
Columbia Lung/Canadian Institutes of Health Research Investigator Award. He is also a recipient of a Michael Smith Foundation for Health Research Distinguished Scholar Award.

ETHICS: The study was approved by either a local institutional ethics board or a centralized ethics board. Participants in this study gave written informed consent.

CONFLICTS OF INTEREST: Drs FitzGerald and Ford have been members of advisory boards for a number of pharmaceutical companies, including the sponsors of this trial. They are also members of speakers bureau for these companies. Both Jennifer Haddon and Caroline Bradley-Kennedy are employees of Boehringer Ingelheim. Lisa Kuramoto has no conflict of interest.

THE RUSIC STUDY GROUP: The full list of investigators include: Drs Susanne Arndt, Saskatchewan; John Axler, Ontario; Spencer Barclay, Nova Scotia; John Bartlett, Ontario; Kenneth Bayly, Saskatchewan; Ronald Bennett, British Columbia; Ira Bernstein, Ontario; Edwin Brankston, Ontario; Kenneth Chapman, Ontario; Stephen Coyle, Manitoba; Tom Crichton, Ontario; Gordon Dyck, Manitoba; Alan Faiers, Ontario; Didier Fay, Quebec; Stephen Field, Alberta; George Fox, Newfoundland; J Mark FitzGerald, British Columbia; Gordon Ford, Alberta; Gregg Garrioch, Ontario; Louis-Marie Gauthier, New Brunswick; William Gracey, Ontario; Robert Hauptman, Alberta; Paul Hernandez, Nova Scotia; Kay Ho, British Columbia; Victor Hoffstein, Ontario; Subodh Kanani, Ontario; Alan Kaplan, Ontario; Pierre Leblanc, Quebec; Alex Leung, British Columbia; Keith Lummack, Ontario; SF Paul Man, British Columbia; Jean-Marie Martel, Quebec; Denis O'Donnell, Ontario; Michael O'Mahony, Ontario; Jean-Pascal Ouellet, Quebec; Walter Owsianik, Ontario; Edward Papp, Alberta; Kim Papp, Ontario; Paul Piechota, Quebec; Gerard Quinn, Ontario; Mohunlall Soowamber, Quebec; Chris Spirou, Ontario; Pearce Wilcox, British Columbia; William Swales, Ontario; Avery Teplinsky, Ontario; Frances Tung, Ontario; Barry Turchen, British Columbia; Douglas Tweel, Prince Edward Island; Richard Tytus, Ontario; and Brian Zidel, Ontario.

\section{REFERENCES}

1. O'Donnell DE, Aaron S, Bourbeau J, et al. State of the Art Compendium: Canadian Thoracic Society recommendations for the management of chronic obstructive pulmonary disease. Can Resp J 2004;11(Suppl B):7B-59B.

2. Murray CJL, Lopez AD, eds. The global burden of disease: A comprehensive assessment of mortality and disability from diseases, injuries, and risk factors in 1990 and projected to 2020. Cambridge: Harvard University Press, 1996.

3. American Thoracic Society. Standards for the diagnosis and care of patients with chronic obstructive pulmonary disease. Am J Respir Crit Care Med 1995;152:S77-120.

4. Lacasse Y, Brooks D, Goldstein RS. Trends in the epidemiology of COPD in Canada, 1980 to 1995. COPD and Rehabilitation Committee of the Canadian Thoracic Society. Chest 1999;116:306-13.

5. Canadian Institute for Health Information, Canadian Lung Association, Health Canada, Statistics Canada. Respiratory disease in Canada. Ottawa, Ontario: Health Canada, 2001.

<http://www.phac-aspc.gc.ca/publicat/rdc-mrc01/pdf/rdc0901e.pdf> (Version current at February 19, 2006).

6. Donaldson GC, Seemungal TA, Bhowmik A, Wedzicha JA. Relationship between exacerbation frequency and lung function decline in chronic obstructive pulmonary disease. Thorax 2002;57:847-52.

7. Miravitlles M, Murio C, Guerrero T, et al. Pharmacoeconomic evaluation of acute exacerbations of chronic bronchitis and COPD. Chest 2002;121:1449-55. 
8. Lau AC, Yam LY, Poon E. Hospital re-admission in patients with acute exacerbation of chronic obstructive pulmonary disease. Respir Med 2001;95:876-84.

9. Burge PS, Calverley PM, Jones PW, Spencer S, Anderson JA, Maslen TK. Randomised, double blind, placebo controlled study of fluticasone propionate in patients with moderate to severe chronic obstructive pulmonary disease: The ISOLDE trial. BMJ 2000;320:1297-303.

10. Dusser D, Bravo ML, Iacono P. The effect of tiotropium on exacerbations and airflow in patients with COPD. Eur Respir J 2006;27:547-55.

11. American Thoracic Society. Standardization of Spirometry, 1994 Update. Am J Respir Crit Care Med 1995;152:1107-36.

12. Wijnhoven HA, Kriegsman DM, Hesselink AE, de Haan M, Schellevis FG. The influence of co-morbidity on health-related quality of life in asthma and COPD patients. Respir Med 2003;97:468-75.

13. van Manen JG, Bindles PJ, Dekker FW, IJzermans CJ, van der Zee JS, Schade E. Risk of depression in patients with chronic obstructive pulmonary disease and its determinants. Thorax 2002;57:412-6.

14. Mokhlesi B. Clinical implications of gastroesophageal reflux disease and swallowing dysfunction in COPD. Am J Respir Med 2003;2:117-21.

15. Global Initiative for Chronic Obstructive Lung Disease. 2004 Update: Workshop report, global strategy for the diagnosis, management, and prevention of COPD.

<http:/www.goldcopd.org/Guidelineitem.asp?11 =2\&12=1\&intId=13 85 \&archived =1 $>$ (Version current at February 26, 2006).

16. de Melo MN, Ernst P, Suissa S. Rates and patterns of chronic obstructive pulmonary disease exacerbations. Can Respir J 2004; 11:559-64.

17. Davies L, Angus RM, Calverley PM. Oral corticosteroids in patients admitted to hospital with exacerbations of chronic obstructive pulmonary disease: A prospective randomised controlled trial. Lancet 1999;354:456-60.
18. Wood-Baker RR, Gibson PG, Hannay M, Walters EH, Walters JA. Systemic corticosteroids for acute exacerbations of chronic obstructive pulmonary disease. Cochrane Database Syst Rev 2005:CD001288.

19. Aaron SD, Vandemheen KL, Hebert P, et al. Outpatient oral prednisone after emergency treatment of chronic obstructive pulmonary disease. N Engl J Med 2003;348:2618-25.

20. Seemungal T, Harper-Owen R, Bhowmik A, et al. Respiratory viruses, symptoms, and inflammatory markers in acute exacerbations and stable chronic obstructive pulmonary disease. Am J Respir Crit Care Med 2001;164:1618-23.

21. Anthonisen NR, Manfreda J, Warren CP, Hershfield, Harding GK, Nelson NA. Antibiotic therapy in exacerbations of chronic obstructive pulmonary disease. Ann Intern Med 1987;106:196-204.

22. Choi PP, Day A, Etchells E. Gaps in the care of patients admitted to hospital with an exacerbation of chronic obstructive pulmonary disease. CMAJ 2004;170:1409-13.

23. Monninkhof EM, van der Valk PD, van der Palen J, et al. Selfmanagement education for chronic obstructive pulmonary disease. Cochrane Database Syst Rev 2003:CD002990.

24. Bourbeau J, Julien M, Maltais F, et al. Reduction of hospital utilization in patients with chronic obstructive pulmonary disease: A disease-specific self-management intervention. Arch Intern Med 2003;163:585-91.

25. Lacasse Y, Brosseau L, Milne S, et al. Pulmonary rehabilitation for chronic obstructive pulmonary disease. Cochrane Database Syst Rev 2002:CD003793.

26. Brooks D, Lacasse Y, Goldstein RS. Pulmonary rehabilitation programs in Canada: National survey. Can Respir J 1999;6:55-63.

27. Seemungal TA, Donaldson GC, Paul EA, Bestall JC, Jeffries DJ, Wedzicha JA. Effect of exacerbation on quality of life in patients with chronic obstructive pulmonary disease. Am J Respir Crit Care Med 1998;157:1418-22.

28. Soler-Cataluna JJ, Martinez-Garcia MA, Roman Sanchez P, Salcedo E Navarro M, Ochando R. Severe acute exacerbations and mortality in patients with chronic obstructive pulmonary disease. Thorax 2005;60:925-31 


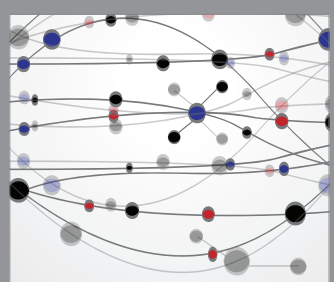

The Scientific World Journal
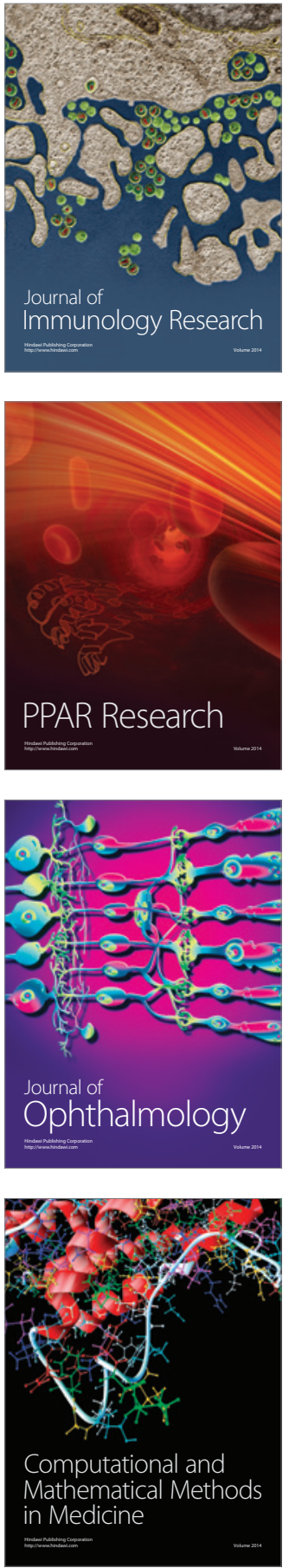

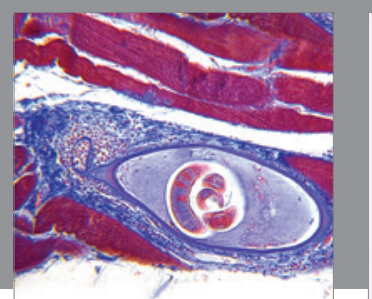

Gastroenterology Research and Practice

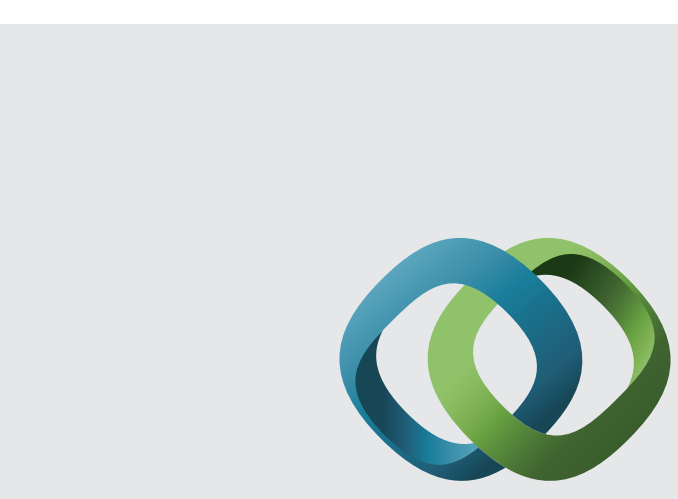

\section{Hindawi}

Submit your manuscripts at

http://www.hindawi.com
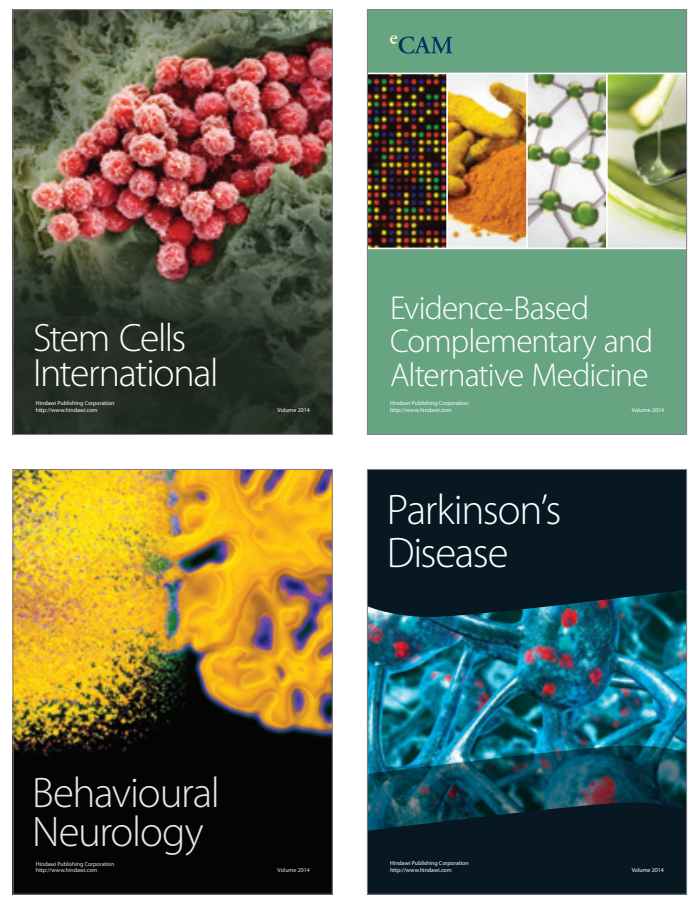
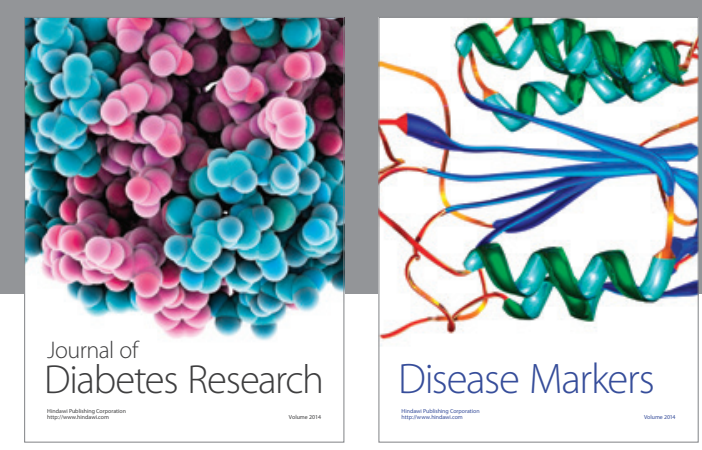

Disease Markers
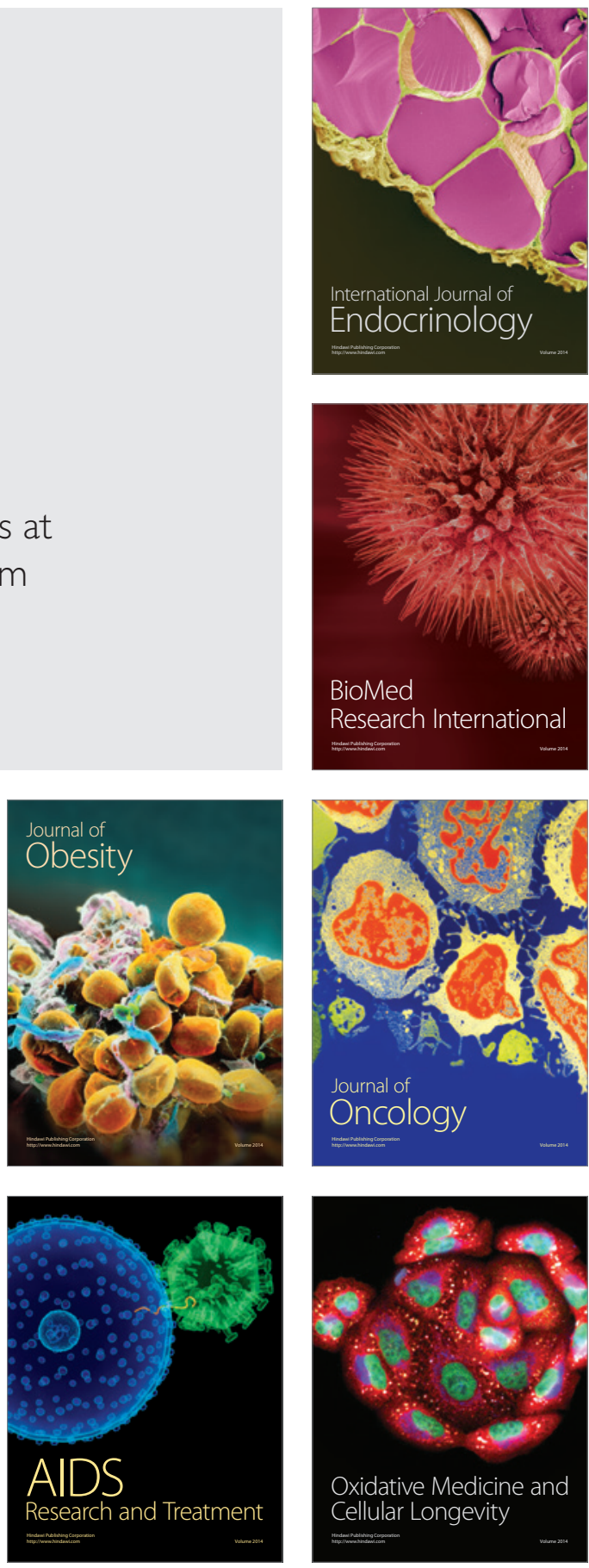